\title{
Origin of males by genome loss in an autoparasitoid wasp
}

\author{
MARTHA S. HUNTER* $\ddagger$ UZI NUR $\dagger \&$ JOHN H. WERREN $\dagger$ \\ *Department of Entomology, Cornel/ University, Ithaca, NY 14853 and tDepartment of Biology, University of Rochester, \\ Rochester, NY 14627, U.S.A.
}

\begin{abstract}
Autoparasitoid wasps lay fertilized (female) eggs in homopteran nymphs and unfertilized (male) eggs in immature parasitoids, often in females of their own species. Autoparasitoid host relationships are generally obligate; a male egg will not develop in the homopteran host even if laid there. While sex is controlled by the female by selective fertilization of eggs, the sex ratio is constrained by the availability of the appropriate hosts. However, in a population of the autoparasitoid Encarsia pergandiella in Ithaca, NY, some of the males develop, like females, as primary parasitoids of whiteflies. A cytogenetic examination of eggs laid in whiteflies revealed that these 'primary' males are haploid, but develop from fertilized eggs. Following fertilization, one set of chromosomes becomes overcondensed and is lost, thus converting the fertilized (female) egg into a haploid (male) egg. Genetic analysis suggests that the production of primary males is heritable; males that develop from parasitoid hosts do not produce primary sons, whereas primary males do. However, the transmission and/or expression of the primary male trait is low and variable. Only about 50 per cent of primary male matings result in any primary sons, and only about 28 per cent of all offspring produced on whiteflies are male. X-irradiation of primary males had no effect on the number of primary sons produced but greatly reduced the number of daughters, suggesting that it is the paternal genome that is lost in the production of primary males. Paternal inheritance of genome loss has been described in one other parasitic wasp, Nasonia vitripennis (Walker). There, chromosome loss is caused by a supernumerary chromosome (PSR). A supernumerary chromosome was not observed in the primary male E. pergandiella. It is unknown how widespread primary male production is among populations of E. pergandiella and other autoparasitoids.
\end{abstract}

Keywords: cytogenetics, Encarsia pergandiella, heteronomous hyperparasitoid, Hymenoptera, paternal genome loss, sex ratio distorter.

\section{Introduction}

Haplodiploid insects and mites are known to adjust the sex ratio of their offspring in response to a variety of environmental factors, and in ways which appear to be adaptive to individuals (for reviews see Waage, 1986, Werren, 1987a). In addition, non-Mendelian elements have been discovered in parasitic wasps that distort the sex ratio, often to the advantage of the element (Werren et al., 1988; Stouthamer et al., 1990). Some of these are micro-organisms that are transmitted only through the egg and increase their frequency by increasing the pro-

$\Varangle$ Correspondence: Department of Entomology, Texas A\&M University, Cullege Station, TX 77843, U.S.A. portion of daughters that a female produces. In an extreme case, bacteria appear to be responsible for thelytoky (parthenogenesis) in some species of Trichogramma (Stouthamer et al., 1990). In one haplodiploid parasitic wasp, Nasonia vitripennis, recent studies revealed both female-biasing and male-biasing genetic elements (Skinner, 1982; Werren et al., 1986; Nur et al., 1988). Of particular interest in the context of this study is the PSR (paternal sex ratio) chromosome. PSR is a supernumerary chromosome that is transmitted through males and causes loss of all the paternal chromosomes but itself in early development of fertilized eggs. PSR thus converts incipient female (diploid) eggs into haploid males (Werren et al., 1987; Nur et al., 1988; Werren, 1991). The chromosome perpetuates itself in populations with female-biased sex ratios 
(Werren, 1987b; Skinner, 1986). Aside from their compelling interest as examples of evolutionary craftsmanship, sex ratio distorters are likely to have profound effects on the genetic and ecological population structure of their carriers.

Encarsia pergandiella Howard is in a group of parasitic wasps in the Aphelinidae that have been called "heteronomous" (Walter, 1983); males and females exhibit different host relationships. E. pergandiella, in particular, is an "autoparasitoid" (Walter, 1983). Females in this species develop as primary parasitoids of whiteflies (called primary hosts), and males normally develop as secondary parasitoids of primary parasitoid pupae (called secondary hosts), often developing on females of their own species. Many species of autoparasitoids occur in the Aphelinidae, and parasitize a variety of whiteflies and armoured scale insects of economic importance. The host relationships in this group are obligate; virgin females may produce haploid sons on secondary hosts but typically refrain from ovipositing in primary hosts, even if these are the only hosts available (Hunter, 1991). Furthermore, when a virgin female does lay unfertilized (male) eggs in a primary host these eggs do not develop (Hunter, 1991). Why unfertilized eggs cannot mature in the primary host and, more generally, how autoparasitoid behaviour has evolved are unsolved puzzles (Walter, 1988). Clearly, however, the sex-specific host relationships constrain the degree to which females can control the sex ratio. Recently, in a population of $E$. pergandiella in Ithaca, NY, unusual males were found that can actually develop on the primary (whitefly) host (Homoptera: Aleyrodidae) (Hunter, 1991). These males (called primary males, in contrast to the normal hyperparasitic secondary males) are common in the field; up to 39 per cent of the males reared from field samples developed on the primary host (Hunter, 1991). The discovery of primary males offers the potential of obtaining insight into the mechanics and evolution of the sex ratio constraint in autoparasitoids.

In this paper we present genetic and cytogenetic evidence that primary males in $E$. pergandiella are haploid and result from the loss of the paternal set of chromosomes shortly after fertilization. Only males that develop from fertilized eggs in this way may themselves produce primary males.

\section{Materials and methods}

\section{Cultures}

Most Encarsia pergandiella, used in this study, were cultured in the laboratory from material initially collected from Trialeurodes packardi (Morrill) on jewel- weed (Impatiens pallida Nutt.) in Ithaca, NY. Primary males were abundant in the Ithaca field population (Hunter, 1991). Some of the males used for karyotyping were obtained from a population from Hanover, $\mathrm{NH}$, where primary males were apparently absent. In the laboratory, E. pergandiella was reared on the greenhouse whitefly, Trialeurodes vaporariorum (Westw.) on bean plants, Phaseolus vulgaris L. Although it is possible that the difference in host species $(T$. vaporariorum in the laboratory and $T$. packardi in the field) may influence the expression of primary males, we think it unlikely because $T$. vaporariorum is also a natural host for $E$. pergandiella (Vet \& Van Lenteren, 1981). In experiments, early fourth instar whitefly nymphs were used as primary hosts and prepupal to early pupal E. pergandiella were used as secondary hosts. As a result of laboratory culturing methods, virtually all of the males present in the cultures at the time of female emergence were primary males. Further details of culturing can be found in Hunter (1991).

\section{Cytogenetics}

E. pergandiella eggs were dissected from the hosts and then fixed for 3-10 min in a mixture of chloroform, ethanol and glacial acetic acid (4:3:1, by volume). The material was stained on the slide for about $15 \mathrm{~min}$ by adding a drop of 2 per cent lacto-aceto-orcein. The eggs were examined at $1000 \times$, using phase-contrast optics.

Using this procedure, 435 eggs of different ages were examined. The majority of these were eggs laid in primary hosts by females that had mated with primary males, and were thus assumed to include both female and primary male eggs. In addition, 35 eggs laid by females that mated with secondary males were examined. As females mated to secondary males produced only daughters on primary hosts (see Results), all of these eggs were assumed to be female. In addition, 10 eggs laid in secondary hosts (early pupal E. pergandiella) were observed. These were presumably normal male eggs, and were thus expected to be unfertilized.

Oogenesis was studied in oocytes dissected from adult females that were fixed as before. Oocytes were stained in 1 per cent lacto-aceto-orcein. Mitotic figures were studied in testes dissected from male pupae in a drop of Ringer's solution, and incubated in a hypotonic colchicine solution $(0.1$ per cent $\mathrm{w} / \mathrm{v}$ colchicine dissolved in 60 per cent Ringer's: 40 per cent distilled water) for $20 \mathrm{~min}$. Testes were then stained with 2 per cent lacto-aceto-orcein for $15 \mathrm{~min}$. Mitotic figures were observed at $1000 \times$ with phase contrast optics. Further details of methods are described in Hunter (1991). 


\section{Results}

Production of primary males by primary and secondary males

To investigate the inheritance pattern of primary male production, females were taken form the stock culture and individually provided with primary hosts (for $24 \mathrm{~h}$ ) and then with secondary hosts (for $24 \mathrm{~h}$ ). Progeny of these females were used in mating experiments. Virgin females were mated to primary males, to secondary males from families with primary males, or to secondary males from families without primary males. Matings among the families were randomly assigned, but sibling matings were excluded. A maximum of one individual of each type (female, or male of a particular category) was used per family. The mated females were introduced to leaf cages that enclosed whitefly nymphs (primary hosts) for $24 \mathrm{~h}$. The progeny of the experimental females were then reared and scored for primary male production.

None of the 31 females mated to secondary males produced any primary male offspring, regardless of whether these secondary males came from families that produced primary males (Fig. 1). These females behaved as if they were typical autoparasitoids, able to produce only females on primary hosts. In contrast, eight of the 14 females mated to primary males produced families in which some or all of the offspring were primary males (Fig.1). Results clearly indicate that only males that developed in primary hosts are themselves capable of producing primary sons.

\section{Distribution of progeny sex ratios on primary hosts}

In order to obtain additional information about the variation in primary male production, 50 females were introduced individually to leaf cages enclosing primary hosts for $24 \mathrm{~h}$. These females were drawn from laboratory cultures where virtually all males were primary (see above) but matings were not controlled and thus the number of matings and the identity of the male was not determined. Progeny were reared and scored for primary male production.

The progeny sex ratios were highly variable (Fig. 2). Half of the females produced only female offspring on primary hosts (Fig. 2). The other half produced either mixed primary families of males and females, or all primary male families (Fig. 2).

Table 1 shows the distribution of sex ratios on primary hosts for females mated (or presumed mated) with primary males for five different experiments: the two inheritance experiments reported here, the control treatment of the irradiation experiment (see below) and two experiments described elsewhere (Hunter, 1991).

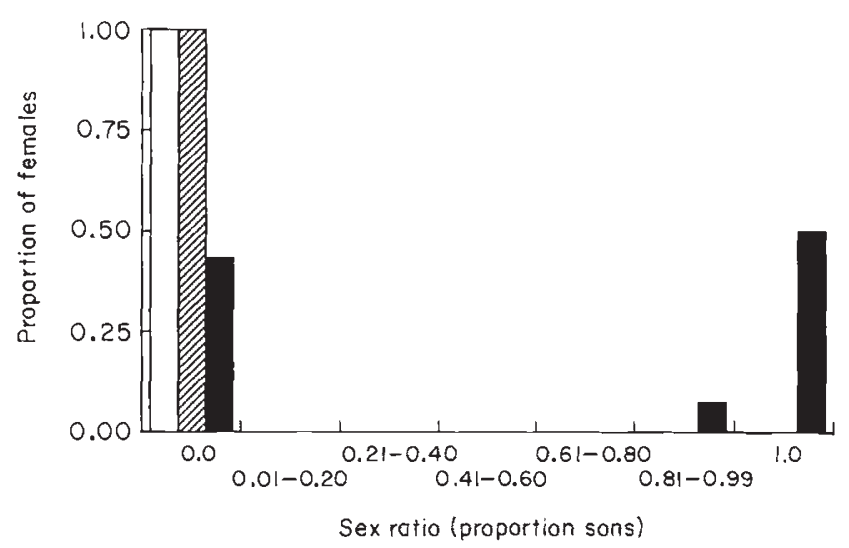

Fig. 1 Progeny sex ratios of females mated to secondary males with primary brothers $(\square), n=20$, secondary males without primary brothers $(\square), n=11$, and primary males with secondary brothers $(\square), n=14$. All of the progeny were produced from primary hosts.

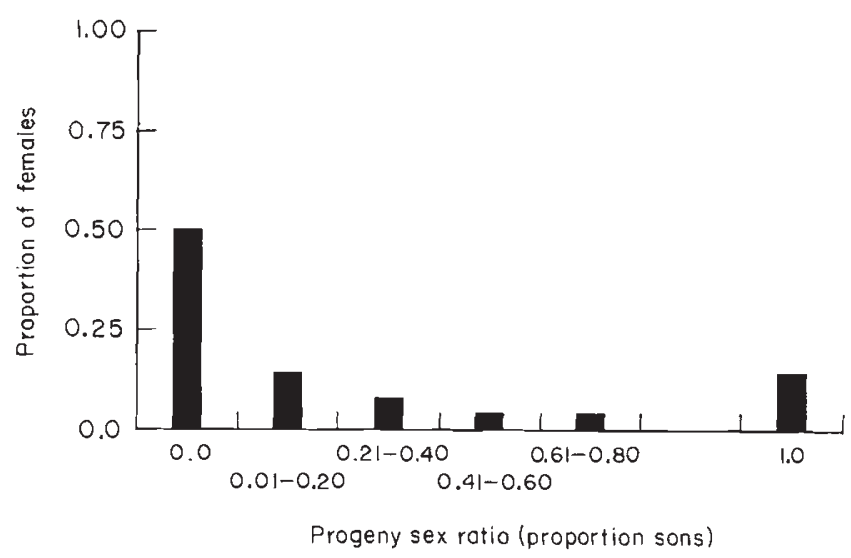

Fig. 2 Frequency distribution of progeny sex ratios on primary hosts. Females were assumed to have mated with one or more primary males (see methods) $(n=50)$.

In each experiment approximately 50 per cent of the females produced only daughters on primary hosts (Table 1). The other females produced at least some primary male offspring; between 14 and 50 per cent of the females produced all primary males, and between 7 and 36 per cent produced mixed families of primary males and females (Table 1). Across the five experiments ( $n=1191$ wasps from 143 families), 28 per cent of offspring produced on primary hosts were male (Table 1). Mean family sizes differed with the type of family produced across experiments (Friedman's method, $\left.\chi_{2 \text {.d.f. }}^{2}=6.4, P<0.05\right)$. In particular, the mean family size of females that produced only primary sons appeared to be smaller than those that produced some or all daughters (Table 1). 
Table 1 Families of different types produced on primary hosts. In these experiments, females were either mated singly to a primary male ('paired mating to primary male') or taken from culture emergence cages where most males were primary ('uncontrolled mating')

\begin{tabular}{|c|c|c|c|c|c|c|c|c|c|}
\hline \multirow[b]{2}{*}{ Experiment } & \multirow[b]{2}{*}{$n^{*}$} & \multicolumn{2}{|c|}{ Daughters only } & \multicolumn{2}{|c|}{ Primary sons only } & \multicolumn{2}{|c|}{$\begin{array}{l}\text { Daughters and } \\
\text { primary sons }\end{array}$} & \multirow[b]{2}{*}{$\begin{array}{l}\text { Sex ratio } \\
\text { (all } \\
\text { progeny) }\end{array}$} & \multirow[b]{2}{*}{$\begin{array}{l}\text { Mean } \\
\text { family } \\
\text { sex ratio } \\
\text { (S.E.) }\end{array}$} \\
\hline & & $\begin{array}{l}\text { Propor- } \\
\text { tion of } \\
\text { families }\end{array}$ & $\begin{array}{l}\text { Mean } \\
\text { family } \\
\text { size (S.E.) }\end{array}$ & $\begin{array}{l}\text { Propor- } \\
\text { tion of } \\
\text { families }\end{array}$ & $\begin{array}{l}\text { Mean } \\
\text { family } \\
\text { size (S.E.) }\end{array}$ & $\begin{array}{l}\text { Propor- } \\
\text { tion of } \\
\text { families }\end{array}$ & $\begin{array}{l}\text { Mean } \\
\text { family } \\
\text { size (S.E.) }\end{array}$ & & \\
\hline \multicolumn{10}{|c|}{ Paired mating to primary male } \\
\hline $1^{\circ} \mathrm{vs} .2^{\circ}$ male mates & 14 & 0.43 & $\begin{array}{c}6.17 \\
(2.55)\end{array}$ & 0.5 & $\begin{array}{c}6.43 \\
(1.07)\end{array}$ & 0.07 & 10 & 0.587 & $\begin{array}{c}0.564 \\
(0.136)\end{array}$ \\
\hline $\begin{array}{l}1^{\circ} \text { Control-irradiation } \\
\text { experiment }\end{array}$ & 18 & 0.56 & $\begin{array}{c}5.6 \\
(1.45)\end{array}$ & 0.28 & $\begin{array}{l}3.8 \\
(0.92)\end{array}$ & 0.17 & $\begin{array}{c}7.67 \\
(0.33)\end{array}$ & 0.265 & $\begin{array}{c}0.331 \\
(0.11)\end{array}$ \\
\hline $\begin{array}{l}\text { Mating status } \\
\text { experiment } \dagger\end{array}$ & 39 & 0.43 & $\begin{array}{c}7.06 \\
(0.92)\end{array}$ & 0.23 & $\begin{array}{l}3.33 \\
(0.69)\end{array}$ & 0.33 & $\begin{array}{c}8.31 \\
(1.16)\end{array}$ & 0.282 & $\begin{array}{l}0.368 \\
(0.07)\end{array}$ \\
\hline \multicolumn{10}{|l|}{ Uncontrolled mating } \\
\hline $\begin{array}{l}\text { Distribution of sex } \\
\text { ratios }\end{array}$ & 50 & 0.5 & $\begin{array}{c}11.84 \\
(0.89)\end{array}$ & 0.14 & $\begin{array}{c}7.43 \\
(2.83)\end{array}$ & 0.36 & $\begin{array}{l}11.56 \\
(0.76)\end{array}$ & 0.218 & $\begin{array}{l}0.245 \\
(0.05)\end{array}$ \\
\hline $\begin{array}{l}\text { Observation } \\
\text { experiment } \dagger\end{array}$ & 22 & 0.5 & $\begin{array}{c}8.36 \\
(1.03)\end{array}$ & 0.23 & $\begin{array}{l}6.4 \\
(2.11)\end{array}$ & 0.27 & $\begin{array}{l}10.33 \\
(0.95)\end{array}$ & 0.323 & $\begin{array}{l}0.355 \\
(0.09)\end{array}$ \\
\hline Total & 143 & 0.48 & $\begin{array}{c}8.72 \\
(2.88)\end{array}$ & 0.23 & $\begin{array}{c}5.39 \\
(3.35)\end{array}$ & 0.29 & $\begin{array}{l}10.02 \\
(2.01)\end{array}$ & 0.277 & $\begin{array}{l}0.338 \\
(0.15)\end{array}$ \\
\hline
\end{tabular}

*Females that produced progeny.

$\nmid$ Experiments described in Hunter (1991).

\section{Oogenesis}

In order to determine whether primary males develop from fertilized or unfertilized eggs, 30 eggs, each from a different female, were dissected from primary hosts within $15 \mathrm{~min}$ of oviposition. In all 30 eggs laid in primary hosts, sperm was visible in the cytoplasm (Fig. 3). Although it could not be determined whether any individual female would produce females or primary males, the probability of finding only female eggs, assuming that 28 per cent of primary offspring are primary males is $P<0.0001$. This result suggests that primary males (as well as females) develop from eggs that have been fertilized.

\section{First mitotic division}

Given that primary males arise from fertilized eggs, they either develop as diploid males, or one chromosome set must be lost following fertilization. A cytogenetic study of post-fertilization development was therefore conducted on normal and primary male eggs.

In most eggs laid in primary hosts by females mated with primary males, first cleavage division of the zygote generally occurs between $1 \mathrm{~h} 40 \mathrm{~min}$ and $2 \mathrm{~h} 10 \mathrm{~min}$ after oviposition. The division of the polar body nucleus usually lags behind the zygote nucleus so that when the zygote nucleus is in anaphase, the polar body nucleus is in metaphase or an earlier stage. The mitotic spindle of the dividing zygote nucleus is usually present near the centre of the egg and its axis is parallel to or diagonal to the long axis. The spindle axis of the dividing polar body nucleus is usually perpendicular to the long axis of the egg, and is close to the posterior pole. The two division products of the fused polar body nucleus, one of the cleavage nuclei migrates towards the pasterior pole of the egg and the two cleavage nuclei then straddle the polar body derivatives (Fig. 4a). A smaller sample of female eggs, laid by females mated with secondary males, was also examined and these conformed with the general sequence of events described above.

In contrast to the pattern above, some of the eggs laid in primary hosts by females mated with primary males showed abnormal chromosome condensation. In three of 21 eggs observed in anaphase of the first cleavage division, the amount of chromatin and the number of chromosomes that could be counted suggested that only one set of chromosomes was dividing (Fig. 5). The other set appeared as a loose chromatin mass to one side of the dividing chromosomes, and did not appear to be connected to the mitotic spindle (Fig. 5). 


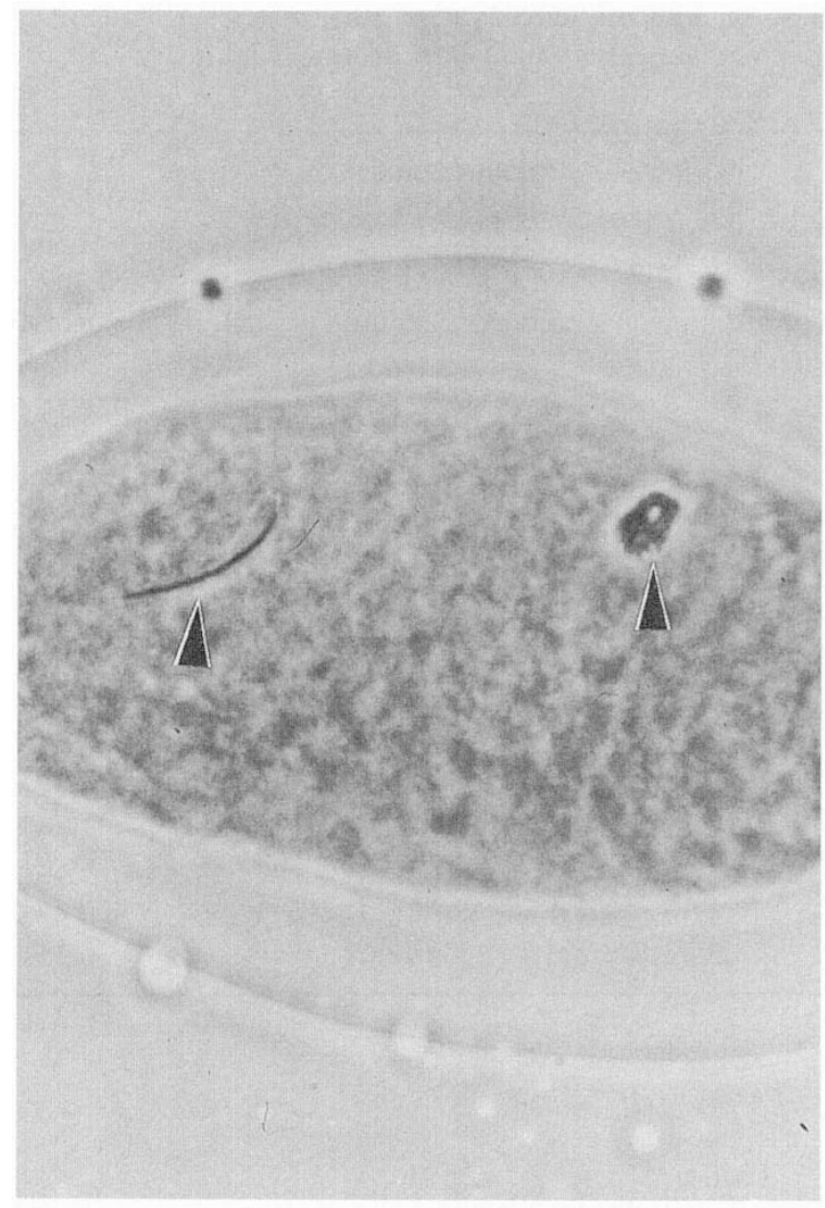

Fig. 3 Newly laid egg. The sperm is visible as a streak in the anterior cytoplasm (left arrow), and the egg pronucleus as a dark staining body (right arrow).

Condensed chromatin was also present between the two interphase nuclei in 25 of 83 eggs observed between first and second cleavage (Fig. 4b). Moreover, in one egg observed at early anaphase of the second cleavage division, only about six chromosomes are seen dividing and there are three clumps of condensed chromatin between the two dividing nuclei (Fig. 6). The observed frequency of abnormal embryogenesis with improperly condensed chromatin (29 of 105 eggs or 28 per cent) is in good agreement with the observed frequency of primary males ( 28 per cent). On the basis of these observations we conclude that primary males develop from fertilized eggs but become haploid because one set of chromosomes fails to condense properly and divide in the first cleavage division. The excluded set of chromosomes then becomes even more condensed, and may be visible as one or more irregular clumps of condensed chromatin until about third cleavage. After third cleavage these clumps are no

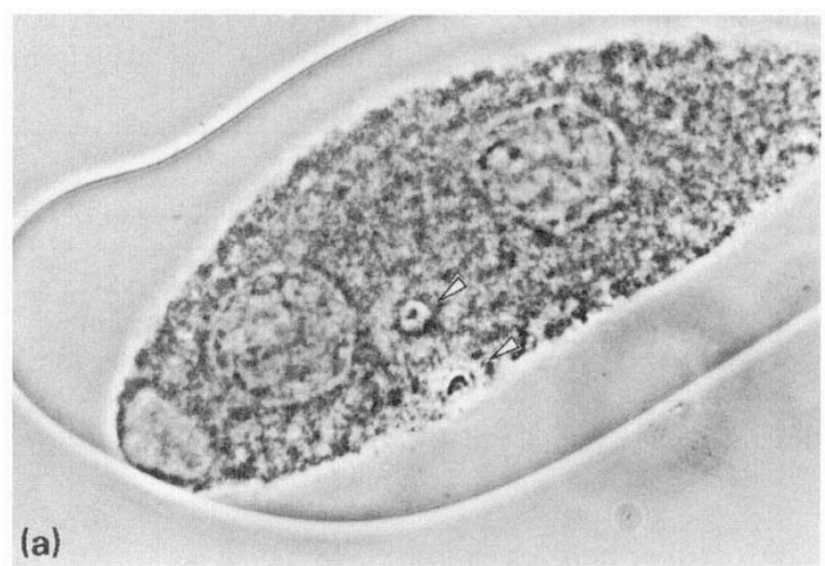

\section{(b)}

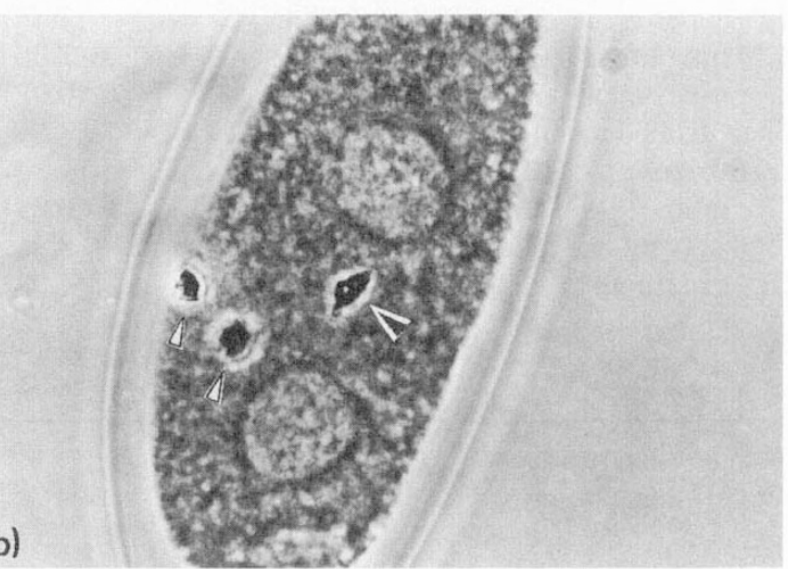

Fig. 4(a) Interphase between first and second cleavage. The two large interphase cleavage nuclei straddle the two small condensed polar body derivatives (white arrows). (b) As above, but in addition to the two polar body derivatives (white arrows) there is condensed chromatin (black arrow) between the two interphase nuclei.

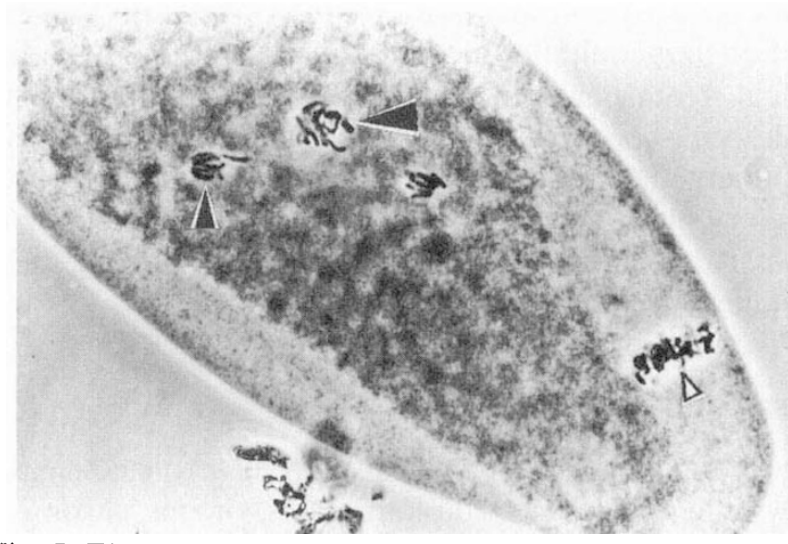

Fig. 5 First cleavage of the less common type. The zygote nucleus is in anaphase (small black arrow) and each group of chromosomes are fewer than the diploid number (12). Above them is a group of chromosomes that is not dividing (large black arrow). The polar body chromosome (white arrow) are outside the cytoplasm to the lower right. The light staining area towards the posterior (right) pole is the oosome. 


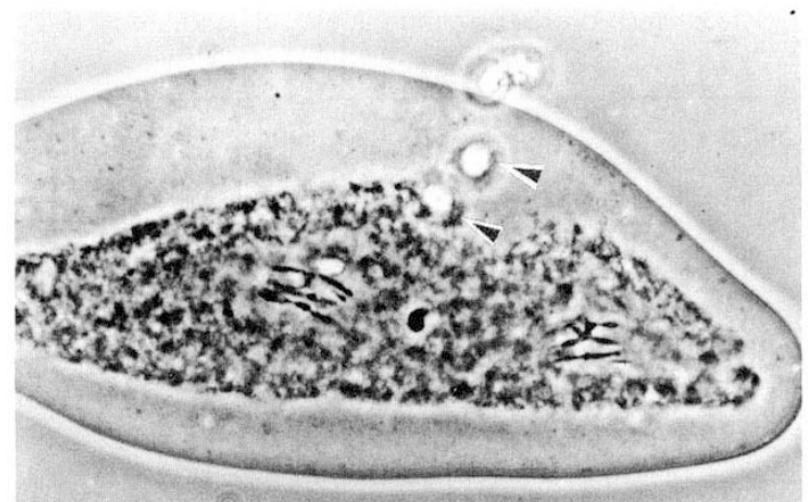

(a)

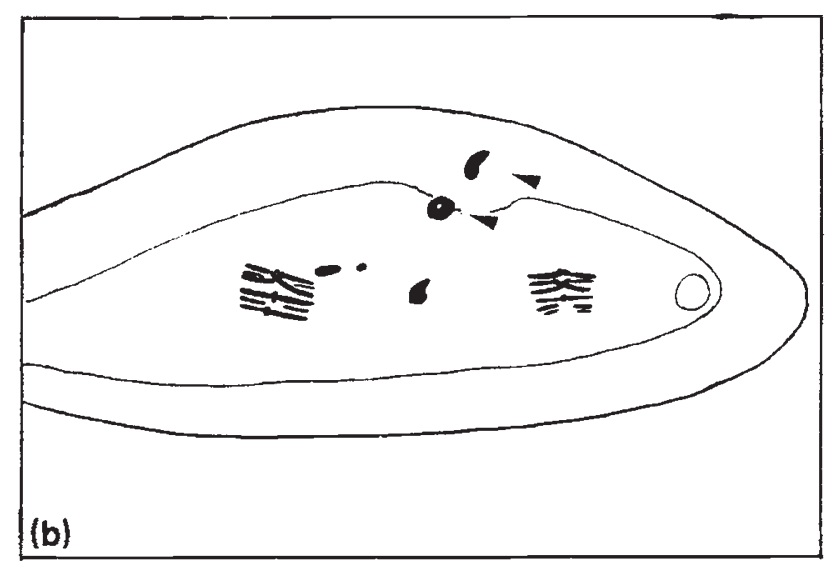

Fig. 6 Photograph and drawing of an egg in early anaphase of second cleavage. There are fewer than the diploid number of chromosomes dividing, and in addition to the two condensed polar body nuclei at the top (black arrows), there are three pieces of condensed chromatin between the two cleavage nuclei. In the photograph the polar body nuclei, and two of the three pieces of chromatin are not in focus and appear as light spots.

longer visible, and it may be assumed that they disintegrate.

\section{The effect of paternal irradiation on primary male production}

The origin of the set of chromosomes that is lost in primary male production was investigated by irradiating males, mating them to virgin females, and providing the females with primary hosts. If the set that is destroyed is of paternal origin, then the genetic damage caused by the irradiation should reduce the number of female progeny produced but not the number of primary male progeny produced. In the first experiment, primary males were randomly allocated to one of three treatments: 'Control', ' $5 \mathrm{kr}$ ', and ' $10 \mathrm{kr}$ '. Adult males were irradiated with $\mathrm{X}$-rays at the appropriate dose, and then each male was confined with a virgin female for $24 \mathrm{~h}$. The experimental females were then introduced to leaf cages with whitefly nymphs for $24 \mathrm{~h}$ and the progeny were reared until emergence. In a second experiment the ' $10 \mathrm{kr}$ ' and 'Control' treatments were repeated, and a 'secondary males $-10 \mathrm{kr}$ ' treatment was added. Because the results of the primary male treatments were not significantly different between experiments, results of like treatments were combined for analysis.

In all of the experimental treatments, the irradiation of primary or secondary males at doses of $5 \mathrm{kr}$ or $10 \mathrm{kr}$ significantly reduced the number of families with daughters relative to those of the primary male controls (Table 2). This result is expected because females develop from fertilized eggs; damage to the paternal set of chromosomes is likely to result in mortality of at least some of the female embryos. In contrast, irradiation did not cause a significant reduction in the number of families of primary males that contained primary sons (Table 2). Nor was there a significant reduction in the mean number of primary sons in the families that included primary males (Table 2). Finally, females mated to irradiated secondary males did not produce any primary sons. This last result makes it unlikely that the process of irradiation somehow promotes the production of primary males by causing paternal chromosome loss in a fertilized egg. These results indicate that the integrity of the paternal set of chromosomes is not necessary for the development of primary males, and therefore that it is the paternal set of chromosomes (rather than the maternal) that is lost in primary males.

\section{Karyotypes}

Karyotypes, of primary and secondary males were studied to test the possibility that, as in the wasp Nasonia vitripennis (Nur et al., 1988; Werren, 1991), the loss of the paternal genome in fertilized eggs is associated with a supernumerary chromosome. In addition to the primary and secondary males examined from the Ithaca population, secondary male $E$. pergandiella collected from a second population (Hanover, $\mathrm{NH}$ on whiteflies on Impatiens capensis Meerb. in August 1990), were examined. A total of 288 females and 299 secondary males were reared from this population but no primary males were found.

Clear karyotypes were observed in seven primary and six secondary males from Ithaca, and in four secondary males from Hanover. The karyotypes of all these males consisted of six chromosomes: five metacentric, and one acrocentric (Fig. 7a-c, e-f). In the acrocentric chromosome the short arm was heterochromatic. All of the five metacentric chromosomes 
Table 2 Progeny production of females mated with irradiated (' $5 \mathrm{kr}$ ', ' $10 \mathrm{kr}$ ') and control primary males and irradiated (' $10 \mathrm{kr}$ ') secondary males

\begin{tabular}{|c|c|c|c|c|c|c|c|}
\hline Treatment & $n$ & $\begin{array}{l}\text { Number of } \\
\text { females } \\
\text { with } \\
\text { daughters }\end{array}$ & $P^{*}$ & $\begin{array}{l}\text { Number of } \\
\text { females } \\
\text { with } \\
1^{\circ} \text { sons }\end{array}$ & $P^{*}$ & $\begin{array}{l}\text { Daughters } \\
\text { per female } \\
\text { with } \\
\text { daughters } \dagger\end{array}$ & $\begin{array}{l}\text { Primary } \\
\text { sons per } \\
\text { female with } \\
\text { sonsł }\end{array}$ \\
\hline Control $-1^{\circ}$ & 28 & 13 & & 8 & & $5.54(1.15)$ & $3.25(0.75)$ \\
\hline $5 \mathrm{kr}-1^{\circ}$ & 18 & 0 & $<0.001$ & 7 & ns & - & $2.14(0.40)$ \\
\hline
\end{tabular}

*Pairwise comparison of the experimental treatment vs. the control (Fisher's exact test).

tMean (S.E.)

$\ddagger$ Mean (S.E.). The means are not significantly different (One-way ANOvA, $F=0.98, P>0.25$ ).

had large blocks of heterochromatin near the centromere, but in at least one of these, one arm was also heterochromatic (Fig. 7c). An examination of two oocytes in early metaphase from one female from Ithaca revealed the presence of six bivalents (Fig. 7d). Thus the haploid number of $E$. pergandiella is $n=6$. No supernumerary (or B) chromosome was observed.

Note that the modal number of chromosomes in the superfamily Chalcidoidea is $n=5$ (Goodpasture \& Grissel, 1975; Crozier, 1977), and five is also the haploid number in the aphelinids Aphytis mytilaspidis (Rössler \& DeBach, 1973) and Aphelinus mali (Viggiani, 1967). In the aphelinid Archenomus orientalis Silvestri, however, the haploid number is 11 (Baldanza et al., 1991), and the reported numbers in other chalcidoids vary from $n=3$ to $n=11$ (Hung, 1986; Strand \& Ode, 1990), including $n=6$ in a few species (Goodpasture \& Grissell, 1975; Goodpasture, 1975).

\section{Elimination of chromatin during spermatogenesis}

In preparations of testes from some of the primary males, it was observed that a densely staining substance, apparently chromatin, is eliminated from the nucleus of some spermatids in the last division of spermatogenesis (Fig. 7g-i). Small densely staining 'dots' were observed outside spermatid nuclei in some of the primary males (Fig. $7 \mathrm{~g}$ ). In another male a bridge of chromatin was seen between two spermatids (Fig. $7 \mathrm{~h})$. In a third male, some of the spermatids had long tails of chromatin with small beads of darkly staining material at the end of some of the tails (Fig. 7i). Among the seven primary and four secondary males observed with early stage spermatids, evidence for the elimination of chromatin was confined to four of the seven primary males. However, at present there is no basis for assuming that the observed chromatin elimination in some of the primary males is related to primary male production.

\section{Discussion}

The experiments investigating the inheritance of primary male production can be summarized as follows: about half of the females mated to primary males produced some or only sons on primary hosts. Females mated to secondary males, in contrast, produced only daughters on primary hosts. All wasps used in the experiment were drawn from the same limited number of families; primary male production thus appears to be inherited in a non-Mendelian manner from father to son. In a haplodiploid system in which males generally develop from unfertilized eggs, the inheritance of paternal traits by haploid males is unexpected. However, we found in the present study that all eggs oviposited in primary hosts were fertilized, and this raises the possibility that something is transmitted to the eggs that develop into primary males from their fathers.

The elimination of the paternal set of chromosomes in fertilized hymenopteran eggs has been observed in cytoplasmic incompatibility reactions in Nasonia vitripennis (Breeuwer \& Werren, 1990; Ryan \& Saul, 1968). Micro-organisms affect the male chromosomes in such a way that they survive only in egg cytoplasm bearing their own strain of microbe. In the Hymenoptera incompatible matings result in all male families (Ryan \& Saul, 1968; Breeuwer \& Werren, 1990). However, these microbes are maternally, rather than paternally, inherited.

An example of a genetic element that is transmitted from father to son in a haplodiploid hymenopteran is the parasitic supernumerary chromosome PSR, carried by some male Nasonia vitripennis (Hym., Pteromalidae) (Werren et al., 1981; Nur et al., 1988; Werren, 1991). Following fertilization of an egg by a PSR-carry- 

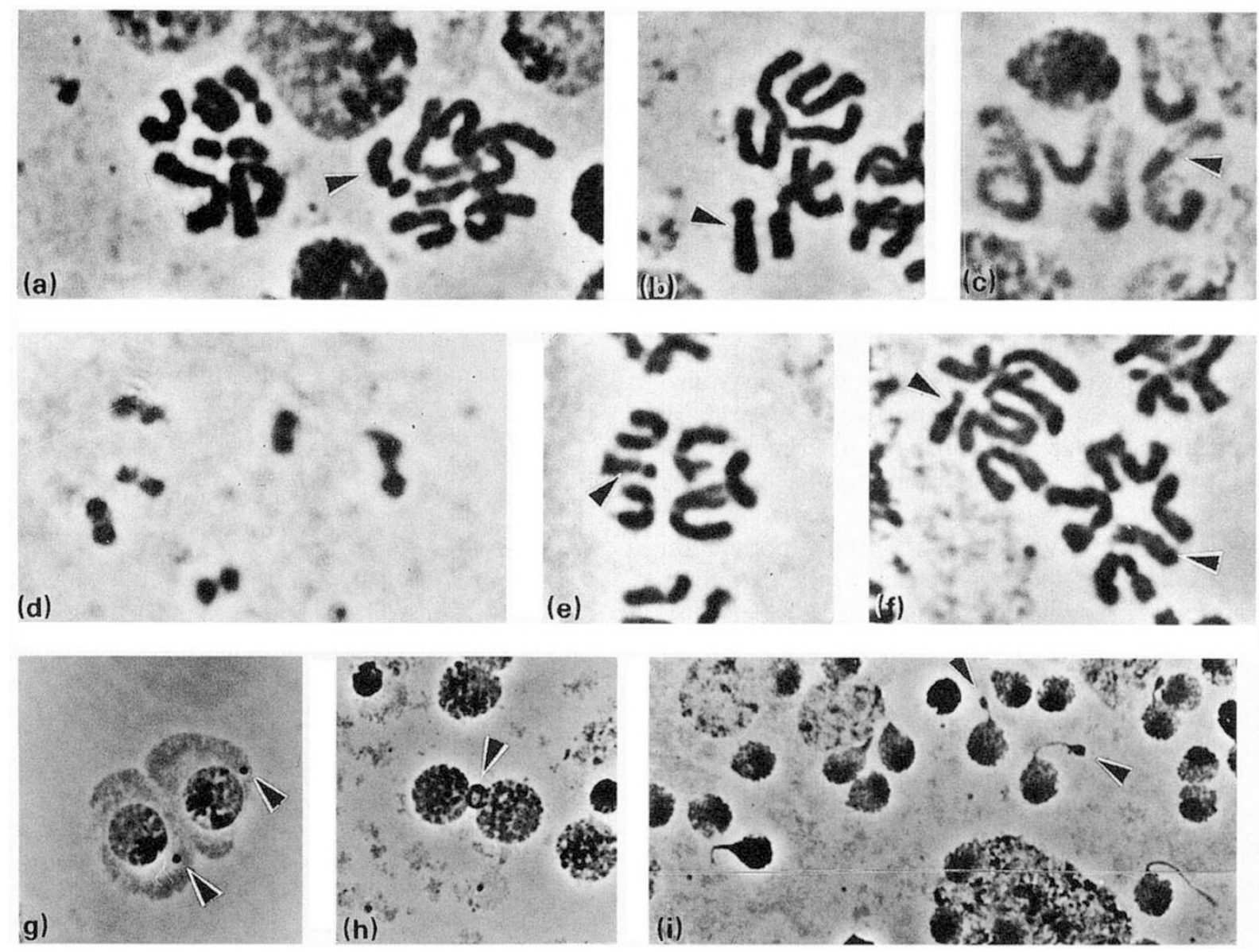

Fig. 7(a-b) Spermatocytes from primary males showing five metacentric and one acrocentric chromosome (arrows). (c) Spermatocyte from a primary male in prophase. All of the chromosomes appear to contain large blocks of heterochromatin near the centromere. (d) Oocyte at early metaphase I showing six bivalents. (e) Karyotypes from an Ithaca secondary male showing five metacentric and one acrocentric chromosome (arrow). (f) Karyotype of a secondary male from a population without primary males (Hanover), also showing five metacentric chromosomes and an acrocentric chromosome (arrow). (g) 'Micronuclei' (arrows) outside of spermatid nuclei (see text for discussion). (h) Chromatin bridge (arrow) between two spermatid nuclei. (i) Spermatid with chromatin 'tails'. Small beads of chromatin are visible at the end of the tails from the two spermatids at centre right (arrows).

ing sperm, the rest of the paternal set of chromosomes becomes condensed, remains mitotically inactive, and is lost. Thus an incipient female becomes another PSRbearing male. As discussed earlier, however, a supernumerary chromosome like PSR is unlikely to be responsible for primary male production in $E$. pergandiella because both primary and secondary males were observed to have six chromosomes (Fig. 7a-c, e-f) and female $E$. pergandiella were found to have 12 chromosomes (Fig. 7d). The inheritance of the ability to convert fertilized eggs into males in E. pergandiella is also much lower than the inheritance of PSR. On average, only 28 per cent of eggs fertilized by sperm from primary males develop into primary males, while PSR causes virtually all fertilized eggs to become male (Werren etal., 1981).
The evidence suggests that the production of primary males may be due to a genetic element transmitted from primary males to their primary male sons. At present the most plausible explanation is that elimination of the paternal genome in eggs that develop into primary males is caused by a transposable element or a paternally inherited virus. One possible alternative explanation, however, is that the production of primary males has no genetic basis but is due to the 'poor' developmental environment of primary hosts for males. Whiteflies are novel hosts for males, and it is possible that spermatogenesis of $E$. pergandiella males in the whitefly host does not proceed normally, and the chromosomes are in some way defective. The male embryo would then again develop in a primary host, and also undergo abnormal spermatogenesis. 
We believe, however, that this explanation is very unlikely. An alternative 'epigenetic' explanation is that genomic imprinting is involved. If fertilization of the eggs results in imprinting modifications of genes necessary for proper processing of chromosomes during spermatogenesis, then primary males, derived from fertilized eggs, would abnormally process sperm chromosomes. This would then result in improper condensation of the paternal chromosomes in fertilized eggs.

The consistent observation that 50 per cent of the females mated to primary males produce no primary sons suggests that a simple Mendelian factor may also be involved, perhaps in the suppression of primary male production. Clearly, further experiments are needed to elucidate the inheritance pattern of this interesting trait.

Invasion of primary males in the Ithaca population of $E$. pergandiella is likely to be due to the extremely high rate of egg fertilization (on average 88 per cent) and female-biased sex ratio (Hunter, 1991). In $E$. pergandiella, sex ratios are driven by the dynamics of the whitefly-parasitoid community and the peculiarity of autoparasitoid biology. The female-biased sex ratios in the Ithaca population occur because hosts for female eggs are an order of magnitude more abundant throughout the season than are secondary hosts for male eggs (Hunter, 1991).

The chronic relative scarcity of secondary hosts is likely in highly seasonal environments where the autoparasitoid population must colonize a patch of unparasitized homopterans and does not greatly increase relative to its host population before the end of the season. It is in these environments that one would predict selection for genetic elements that can produce more males by circumventing the strictures of obligatory autoparasitism. The prevalence of primary males in autoparasitoid populations is unknown but the absence of any reports in the literature, even in studies of E. pergandiella in California (Gerling, 1966; Vet \& van Lenteren, 1981), and New Hampshire (this study) suggests they are not widespread. Surveys of autoparasitoid populations in conjunction with investigations of the population dynamics of the host-autoparasitoid associations are needed to better understand whether these genetic elements are limited by the frequency at which they arise or by opportunities to invade.

\section{Acknowledgements}

We are grateful to J. Woolley and M. Rose at Texas A\&M University for identifying $E$. pergandiella. We would also like to thank C. Godfray, J. Nyrop, A. Power, D. Pimentel and R. Stouthamer for helpful comments on earlier versions of this manuscript. Research support was provided by a NSF Dissertation Improvement Grant to MSH and a NSF grant to JHW.

\section{References}

BALDANZA, F., Gaudio, L. AND VIGGiani, G. 1991. Ricerche cariologiche sull'Archenomus orientalis Silvestri (Hymenoptera: Aphelinidae), parassitoide di Pseudaulacapis pentagona (Targioni Tozzeti) (Homoptera: Diaspididae). Atti XVI Congresso nazionale italiano di Entomologia Bari - Martina Franca (Ta) 23/28 settembre 1991, 457-461.

BREEUWER, J. A. J. AND WERREN, J. H. 1990. Microorganisms associated with chromosome destruction and reproductive isolation between two insect species. Nature, 346, 558-560.

CROzIER, R. H. 1977. Evolutionary genetics of the Hymenoptera. Ann. Rev. Entomol., 22, 263-268.

GERLING, D. 1966. Studies with whitefly parasites of Southern California. I. Encarsia pergandiella Howard (Hymenoptera: Aphelinidae). Can. Entomol., 98, 707-724.

GOODPASTURE, C. 1975. Comparative courtship behavior and karyology in Monodontomerus (Hymenoptera: Torymidae). Ann. Entomol. Soc. Am., 68, 391-397.

GOODPASTURE, C. AND GRISSELL, E. E. 1975. A karyological study of nine species of Torymus (Hymenoptera: Torymidae). Can. J. Genet. Cytol., 17, 413-422.

HuNG, A. C. F. 1986. Chromosomes of three Brachymeria species (Hymenoptera: Chalcididae). Experientia, $\mathbf{4 2}$, 579-580.

HUNTER, M. S. 1991. Sex ratio in an autoparasitoid Encarsia pergandiella Howard (Hymenoptera: Aphelinidae). PhD Thesis, Cornell University, Ithaca, NY.

NUR, U., WERREN, J. H., EICKBUSH, D. G., BURKE, W. D. AND EICKBUSH T. H. 1988. A 'selfish' B chromosome that enhances its transmission by eliminating the paternal genome. Science, 240, 512-514.

RÖSSLER, Y. AND DEBACH, P. 1973. Genetic variability in a thelytokous form of Aphytis mytilaspidis (Le Baron) (Hymenoptera: Aphelinidae). Hilgardia, 42, 149-175.

RYAN, S. L. AND SAUL, II, G. B. 1968. Post-fertilization effect of incompatibility factors in Mormoniella. Mol. Gen. Genet., 103, 29-36.

SKINNER, S. 1982. Maternally inherited sex ratio in the parasitoid wasp Nasonia vitripennis. Science, 2 15, 1133-1134.

SKINNER, S. 1986. Paternal transmission of an extrachromosomal factor in a wasp: evolutionary implications. Heredity, 59, 47-53.

STOUTHAMER, R., LUCK, R. F. AND HAMILTON, w. D. 1990. Antibiotics cause parthenogenetic Trichogramma (Hymenoptera: Trichogrammatidae) to revert to sex. Proc. Natl Acad. Sci., U.S.A., 87, 2424-2427.

STRAND, M. R., AND ODE, P. J. 1990. Chromosome number of the polyembryonic parasitoid Copidosoma floridanum (Hymenoptera: Encyrtidae). Ann. Entomol. Soc. Am., 83, 834-837. 
VET, L. E. M., AND VAN LENTEREN, J. C. 1981. The parasite-host relationship between Encarsia formosa Gah. (Hymenoptera: Aphelinidae) and Trialeurodes vaporariorum (Westw.) (Homoptera: Aleyrodidae).X. A comparison of three Encarsia spp. and one Eretmocerus sp. to estimate their potentialities in controlling whitefly on tomatoes in greenhouses with a low temperature regime. Z. Ang. Ent., 91, 327-348.

VIGGIANI, G. 1967. Richerche sugli Hymenoptera Chalcioidea. XV. Osservazioni cariolgiche preliminari sulli Aphelinus mali. Boll. Lab. Entomol. Agr. 'Filippo Silvestri' Portici., 25, 326-330.

WAAGE, J. K. 1986. Family planning in parasitoids: Adaptive patterns of progeny and sex allocation. In: Waage, J. K. and Greathead, D. (eds) Insect Parasitoids, Academic Press, Boston, pp. 63-95.

WALTER, G. H. 1983. 'Divergent male ontogenies' in Aphelinidae (Hymenoptera: Chalcidoidea): A simplified classification and a suggested evolutionary sequence. Biol. J. Linn. Soc., 19, 63-82.
WALTER, G. H. 1988. Heteronomous host relationships in aphelinids - evolutionary pathways and adaptive significance (Hymenoptera: Chalcidoidea). Ad. Para. Hymenoptera Res., 1988, 313-326.

WERREN, J. H. 1987a. Labile sex ratios in wasps and bees. BioSci., 37, 498-506.

WERREN J. H. $1987 \mathrm{~b}$. The coevolution of autosomal and cytoplasmic sex ratio factors. J. Theor. Biol., 124, 317-334.

WERREN, J. H. 1991. The paternal-sex-ratio chromosome of Nasonia. Am. Nat., 137, 392-402.

WERREN, J. H., NUR, U. AND EICKBUSH, D. 1987. An extrachromosomal factor causing loss of paternal chromosomes. Nature, 327, 75-76.

WERREN, J. H., NUR, U. AND WU, C. I. 1988. Selfish genetic elements. TREE, 3, 297-302.

WERREN, J. H., SKInNER, S. W., AND ChARNov, E. L. 1981. Paternal inheritance of a daughterless sex ratio factor. Nature, 293, 467 468.

WERREN, J. H., SKINNER, S. W. AND HUGER, A. M. 1986. Male-killing bacteria in a parasitic wasp. Science, 231, 990-992. 